\title{
Impact of Pandemic on Women Health Indicators in a Tertiary Health Centre of Bihar
}

\author{
Punit Hans ${ }^{1}$, Anjana Sinha², Uday Kumar ${ }^{3}$ \\ 1, 2 Department of Obstetrics and Gynaecology, Patna Medical College and Hospital, Patna, Bihar, India. \\ ${ }^{3}$ Department of Gastroenterology, Consultant Ford Hospital, Patna, Bihar, India.
}

\section{ABSTRACT}

\section{BACKGROUND}

This study was conducted to analyse the impact of pandemic on healthcare, evaluate the negative psychological behaviour towards health professionals and study the effect of Covid-19 infection on hospital avoiding attitude of female patients.

\section{METHODS}

This was a case-control study conducted in Department of Obstetrics and Gynaecology at Patna Medical College and Hospital, Patna, Bihar. Study period was from 01 ${ }^{\text {st }}$ April 2020 to $30^{\text {th }}$ September 2020. All the patients except Covid-19 positive cases, coming to Gynaecology Outpatient Department (GOPD), antenatal care (ANC) and labour room emergency (LRE) were included in the study. Patients who were seen from April 2019 to September 2019, total of 20,961 were in "pre Covid-19" control group, while patients seen from April 2020 to September 2020, a total of 8,859 were in "during Covid-19" case group. Records of all health parameters for patients were reviewed, and then divided into two groups as patient input indicators and healthcare efficiency indicators. Number of patients visiting GOPD, ANC and admitted in LRE comprised patient input indicators (implying hospital avoiding attitude) while delivery rate, dilation and evacuation (D \& E) rate, stillbirth rate and mortality rate comprised healthcare efficiency indicators.

\section{RESULTS}

Overall patients visiting the hospital dropped down from 21,361 to 8859 (by $58.5 \%$ ); GOPD patients reduced by $74 \%$ while total ANC patients reduced by $44 \%$; and total LRE admissions reduced by $35.3 \%$.

\section{CONCLUSIONS}

Despite increased health professionals (workdays) per patient in LRE, mortality rate and still birth rate increased by $60.2 \%$ and $23 \%$ respectively indicating worsening of efficiency which is direct hidden negative psychological impact of pandemic immediately calling for the need of positive counselling and proper psychiatric care of both the health professionals and patients.

\section{KEY WORDS}

Covid-19, Pandemic, Still Birth Rate
Corresponding Author:

Dr. Punit Hans,

C/O Sri Paramhans Kumar

Hans Niketan, Mukhopadhya Colony,

Opp. Bazar Samiti Main Gate,

Near Rampur Road, P.O - Mahendru,

Patna - 800006, Bihar, India,

E-mail: punit.1628@gmail.com

DOI: $10.14260 / j e m d s / 2021 / 341$

How to Cite This Article:

Hans $P$, Sinha A, Kumar U. Impact of pandemic on women health indicators in a tertiary health centre. J Evolution Med Dent Sci 2021;10(22):1639-1644, DOI: 10.14260/jemds/2021/341

Submission 05-11-2020,

Peer Review 03-04-2021,

Acceptance 10-04-2021,

Published 31-05-2021.

Copyright (c) 2021 Punit Hans et al. This is an open access article distributed under Creative Commons Attribution License [Attribution 4.0 International (CC BY 4.0)] 


\section{BACKGROUND}

The first case of Covid-19 in India was reported on 30 January 2020. The World Health Organisation declared the novel coronavirus disease 2019 (Covid-19) outbreak as a global pandemic on March 11, 2020.1 First case of Covid-19 was seen in Bihar on 22 March 2020 and India enforced one of the world's largest lockdowns on $25^{\text {th }}$ March $2020^{2}$ to minimize the impact of the Covid-19 pandemic. According to WHO, people, efforts and medical supplies all shift to respond to the emergency. This often leads to the neglect of basic and regular essential health services. People with health problems unrelated to the epidemic find it harder to get access to health care services. ${ }^{3}$ The health workforce has been further reduced by nosocomial Covid-19 infection. ${ }^{4}$ The vast majority of stillbirths, $84 \%$, occurred in low and lower-middle-income countries. $^{5}$ A $50 \%$ reduction in health services due to the pandemic could cause nearly 200000 additional stillbirths over a 12-month period in 117 low and middle-income countries. This corresponds to an increase in the number of stillbirths by $11.1 \% .^{5}$ Healthcare professionals already work under highly stressful conditions in labour room emergency and added to their anxiety due to pandemic of Covid-19, adverse effects on doctors and patients are more evident.

As such to know the Covid-19 pandemic mental and physical health effects on non Covid-19 healthcare professionals and its impact on women healthcare in a tertiary centre and coping strategy of a low-income setting (human development index 0.576 in 2018) state Bihar from India (third most populated state, with maternal mortality ratio 294, infant mortality rate 52 , institutional delivery $51.9 \%$, mothers with full ante natal check-up $6 \%$ in the year 2012) ${ }^{6}$ this study was done. This study was conducted to know the impact of pandemic on women health indicators.

\section{METHODS}

\section{Study Design and Participants}

This was a case-control study conducted in the Department of Obstetrics and Gynaecology at Patna Medical College and Hospital, Patna, Bihar. Study period was of six months from $1^{\text {st }}$ April 2020 to $30^{\text {th }}$ September 2020. This study was conducted to analyse the effect of Covid-19 pandemic on a tertiary health care centre in Bihar, and its impact on overall care of female patients with special emphasis on maternal care. They were divided into two groups. All the patients except Covid-19 positive cases, coming to department of GOPD (Gynaecology Outpatient), ANC (Ante-Natal Care) and LRE (Labour Room Emergency) were included in the study. Patients coming to department from April 2019 to September 2019 which included a total of 20,961 were in "pre Covid-19" group acting as control while those who came from April 2020 to September 2020 total of 8,859 were in "during Covid-19" group as case. Cross-sectional study was done on "during Covid-19" group.

\section{Data Sources}

Data was collected during duties and matched with the record room of hospital. Records of all health parameters for patients were reviewed, the parameters with incomplete data were excluded from the study. All the data was arranged on Microsoft Excel 2010 Ink. and calculations were done on this spreadsheet. Health parameters were then divided into two groups as patient input indicators and healthcare efficiency indicators. Number of patients visited GOPD, ANC and admitted in LRE comprised patient input indicators (implying hospital avoiding attitude) while delivery rate, D\& E rate, still birth rate and mortality rate comprised healthcare efficiency indicators.

\section{Definitions and Measurements}

Delivery rate is the total number of deliveries (lower segment caesarean section (LSCS) and normal vaginal deliveries (NVD)\} per 100 LRE admissions. Still birth rate is total still births per 100 deliveries. D \& $\mathrm{E}$ rate is total number of $\mathrm{D} \& \mathrm{E}$ per 100 LRE admissions and Mortality rate is total number of deaths per $100 \mathrm{LRE}$ admissions.

For studying the effect of pandemic, month wise comparison was done between two groups for each indicator and then percent change for each indicator were graded. Grades for pandemic effects on efficiency indicators $= \pm$ delivery rate change $\% \pm$ still birth rate change $\% \pm D$ \& $\mathrm{E}$ rate change $\% \pm$ mortality rate change $\%$ (changes have to be added or subtracted according to their direction of improvement or deterioration, it will be opposite for still birth rate and mortality rate). Grades for combined lockdown and pandemic effects on input indicators $= \pm \%$ change in GOPD $\pm \%$ change in ANC (LRE is not included as emergency services were not under lockdown). Changes in LRE admissions were graded as $\pm \%$ change. Healthcare professionals on monthly rotation duty or temporary duty were all excluded so study was done on total 30 junior doctors (of second and third year only) as they were working regularly in LRE since April 2019 and active cases only confirmed with reverse transcriptase polymerase chain reaction (RT-PCR) test for Covid-19 were included in study. To study the effect of shortage of healthcare professionals due to Covid-19 infection and deployment in Covid-19 duty, total work days available per 100 LRE admissions were calculated for each month in both the study groups.

Total work days available $(\mathrm{W})=$ total work days - lost work days

Total work days $=$ total number of employee $\times$ total working days

Lost workdays = sum of each employee absent days.

Alternatively,

$\mathrm{W}=$ Number of employees (fixed) working per day (D) $\times$ number of working days - absence days for each employee

Assuming total working days as fixed variable and no other leave, total workdays available (W) were directly proportional to the total number of employees. In our scenario (assuming no other leave as its emergency services): Each junior doctor works in LRE two days per week and total 10 days per month, so total working days $=10$.

Total work days available $(\mathrm{W})=$ total number of junior doctors (30) $\times$ total working days (10 or 11) per junior doctor - number of deployed junior doctors $\times$ total working days per junior doctor - Covid-19 absent days (for one week - 2 days, 
for two weeks - 4 days, for 3 weeks - 6 days). Or, in pre pandemic, $\mathrm{W}=\mathrm{D} \times 30$ or 31 days.

\section{Statistical Analysis}

Comparison table was constructed for the external factors influencing the efficiency in both the study groups. Chi-square test was applied and $\mathrm{P}$ value calculated for the difference of total numbers in each indicator between two groups. Month wise performance of healthcare in relation to number of active cases in Bihar was studied on area graph. Data for active cases (on 15th of each month) in Bihar was collected from the website and twitter handle of health department of Bihar. ${ }^{7}$

Student's t-test was applied to measure the effect of pandemic on indicators. Pearson coefficient of correlation was used to predict the relation between the various indicators. To lower the bias due to festivals and seasonal variations, same months from both years (2019 and 2020) were included in the study. Healthcare professionals were also same in both groups.

\section{RESULTS}

As in Table 2, overall patients visiting our department dropped down from 21,361 to 8859 (by $58.5 \%$ ). GOPD patients were decreased by $74 \%$ while total ANC patients decreased by 44 $\%$. During the six months of Covid-19, elective cases dropped drastically by $97 \%$ mainly due to decreased input, confusion and reluctance of patients. Overall mortality rate also increased by $60.2 \%$.

\begin{tabular}{|ccc|}
\hline Factors & $\mathbf{2 0 1 9}$ & $\mathbf{2 0 2 0}$ \\
Tertiary centre & Same & Same \\
Infrastructure & Same & Same \\
Population & Same & Same \\
Time period & Same & Same \\
Seasons & Same & Same \\
Group of health professionals & Same & Same \\
Pandemic (Covid-19) media reporting & Absent & Present \\
Active cases in population & Absent & Present \\
Active cases among health professionals & Absent & Present \\
Avg. workdays per 100 LRE admission & 44.2 & 63.2 (increased) \\
\hline Table 1. Table of Comparison of External Factors \\
\hline
\end{tabular}

\begin{tabular}{|c|c|c|c|c|}
\hline Indicators & 2019 & 2020 & \multicolumn{2}{|c|}{ \% Change } \\
\hline \multicolumn{5}{|c|}{ Patient input indicators (P-value are calculated with Chi-square $2 \times 2$ contingency table of each indicator with total patients visit) } \\
\hline GOPD & 11470 & 2970 & 74.1 (decrease) & $\mathrm{P}<0.00001$ \\
\hline ANC & 5684 & 3169 & 44.24 (decrease) & $\mathrm{P}<0.00001$ \\
\hline LRE admissions & 4207 & 2720 & 35.3 (decrease) & $\mathrm{P}<0.00001$ \\
\hline Total patients visit & 21361 & 8859 & 58.5 (decrease) & \\
\hline \multicolumn{5}{|c|}{ Healthcare efficiency indicators ( $\mathrm{P}$-value are calculated with Chi-square test $2 \times 2$ contingency table) } \\
\hline$\%$ LSCS & $34.8(1465$ / 4207) & $32.75(891 / 2720)$ & 5.8 (decrease) & $P=0.212$ \\
\hline$\%$ NVD & $34.9(1470 / 4207)$ & $39.37(1071 / 2720)$ & 12.8 (increase) & $P=0.011$ \\
\hline$\% \mathrm{D} \& \mathrm{E}$ & $3.77(159 / 4207)$ & $3.1(85 / 2720)$ & 17.7 (decrease) & $P=0.163$ \\
\hline Still birth rate & $5.93(174$ / 2935) & $7.3(143 / 1962)$ & 23 (increase) & $P=0.076$ \\
\hline Mortality rate & $1.33(56 / 4207)$ & $2.13(58 / 2720)$ & 60.2 (increase) & $P=0.0118$ \\
\hline
\end{tabular}

\begin{tabular}{|c|c|c|c|c|c|c|c|c|c|}
\hline Month & $\begin{array}{l}2019 \text { Still } \\
\text { Birth Rate }\end{array}$ & $\begin{array}{l}2020 \text { Still } \\
\text { Birth Rate }\end{array}$ & $\begin{array}{c}\text { \% Change Still } \\
\text { Birth Rate }\end{array}$ & $\begin{array}{c}2019 \text { Mortality } \\
\text { Rate }\end{array}$ & $\begin{array}{c}2020 \\
\text { Mortality Rate }\end{array}$ & $\begin{array}{l}\text { \% Change } \\
\text { Mortality }\end{array}$ & $\begin{array}{l}2019 \text { D \& E } \\
\text { Rate }\end{array}$ & $\begin{array}{c}2020 \text { D \& E } \\
\text { Rate }\end{array}$ & $\begin{array}{c}\text { \% Change D \& } \\
\text { E }\end{array}$ \\
\hline April & 5.95 & 7.36 & -23.7 & 9.1 & 1.256 & -38 & 3.4 & 5.02 & +47.6 \\
\hline May & 5.96 & 6.79 & -13.9 & 1.2 & 2.9 & -142 & 4 & 4.65 & +16.25 \\
\hline June & 7.86 & 6.45 & +17.9 & 1.91 & 2.35 & -23 & 3.6 & 2.35 & -34.7 \\
\hline July & 6.18 & 9.95 & -61 & 1.48 & 1.52 & -2.7 & 4.1 & 1.14 & -72 \\
\hline Aug & 4.24 & 8.88 & -109 & 1.07 & 3.01 & -181 & 4.1 & 2.08 & -49 \\
\hline Sept & 6.02 & 5.76 & +4.3 & 1.39 & 1.75 & -25.9 & 3 & 2.1 & -30 \\
\hline Month & $\begin{array}{l}2019 \text { delivery } \\
\text { rate }\end{array}$ & $\begin{array}{c}2020 \text { delivery } \\
\text { rate }\end{array}$ & $\begin{array}{l}\% \text { change } \\
\text { delivery rate }\end{array}$ & $\begin{array}{l}\text { Overall pandemic } \\
\text { effects on efficiency } \\
\text { (all figures } \\
\text { rounded) }\end{array}$ & 2019 LRE admission & $\begin{array}{l}2020 \text { LRE } \\
\text { admission }\end{array}$ & $\begin{array}{l}\text { Effect on LRE } \\
\text { admission }\end{array}$ & $\begin{array}{l}2019 \text { work days } \\
\text { available per } 100 \\
\text { admission }\end{array}$ & $\begin{array}{c}2020 \text { work days } \\
\text { available per } 100 \\
\text { admission }\end{array}$ \\
\hline April & 58.4 & 70.7 & +39 & +25 & 546 & 557 & +11 (2.01\%) & 55 & 54 \\
\hline May & 68 & 68.4 & 0 & -140 & 666 & 516 & - 150 (22.5\%) & 45 & 60 \\
\hline June & 71 & 64.9 & -8.59 & -48 & 626 & 382 & $-244(38.97 \%)$ & 48 & 75 \\
\hline July & 67.4 & 76.4 & +13.3 & -122 & 743 & 263 & $-480(64.6 \%)$ & 42 & 101 \\
\hline Aug & 75.89 & 73.08 & -3.7 & -343 & 838 & 431 & $-480(57.27 \%)$ & 37 & 52 \\
\hline Sept & 73.7 & 78.98 & +7.1 & -45 & 788 & 571 & $-217(27.5 \%)$ & 38 & 37 \\
\hline Month & 2019 GOPD & 2020 GOPD & $\%$ change GOPD & 2019 ANC & 2020 ANC & $\%$ change ANC & $\begin{array}{r}\text { Combined lock } \\
\text { effect - A }\end{array}$ & $\begin{array}{l}\text { down \& epidemic } \\
\text { ANC + GOPD }\end{array}$ & $\begin{array}{l}\text { Active cases in } \\
\text { Bihar on } 15^{\text {th }} \text { of } \\
\text { each month }\end{array}$ \\
\hline April & 1993 & 200 & -1793 & 991 & 380 & -611 & -2404 & $(80.5 \%)$ & 45 \\
\hline May & 1910 & 429 & -1481 & 1034 & 559 & -475 & -1956 & (66.44\%) & 632 \\
\hline June & 1756 & 690 & -1066 & 885 & 729 & -156 & -1222 & $(46.27 \%)$ & 2357 \\
\hline July & 1979 & 311 & -1668 & 1061 & 330 & -731 & -2399 & $(78.9 \%)$ & 6482 \\
\hline Aug & 1931 & 376 & -1555 & 880 & 411 & -469 & -2024 & $4(72 \%)$ & 32,715 \\
\hline Sept & 1901 & 964 & -937 & 833 & 760 & -73 & -1010 & (36.94\%) & 13,731 \\
\hline
\end{tabular}

According to Table 3, the t-test value and P-value for pandemic effects on health indicators were: still birth rate $t$ value $=1.87369$ and $\mathrm{P}$-value $=.045229$, mortality rate: $\mathrm{t}=$ 2.418 and $\mathrm{P}=.018$ (implying increase in still birth rate and mortality due to pandemic effects), D \& E rate: $t=-1.217$ and $\mathrm{P}=.125$, total delivery rate: $\mathrm{t} 0.916$ and $\mathrm{P}=.190$, LRE admissions: $\mathrm{t}=-3.77$ and $\mathrm{P}=.0018$, ANC: $\mathrm{t}=-4.965$ and $\mathrm{P}=$ .00028 , GOPD: $\mathrm{t}=-11.788$ and $\mathrm{P}=<0.00001$. The $\mathrm{t}$-test value for workdays per $100 \mathrm{LRE}$ admissions in the two groups was $\mathrm{t}$
$=2.002, \mathrm{P}=0.036$ implying increased workdays per $100 \mathrm{LRE}$ admissions during Covid-19, owing to decreased admissions which overshadowed the effects of shortage of healthcare professionals.

Number of active cases of Covid-19 in the state was found to have strong positive correlation with negative pandemic effects on healthcare efficiency (Pearson coefficient $\mathrm{R}=$ $0.8189, \mathrm{P}=0.0462$ ) and moderate positive correlation with negative effects on LRE admissions $(\mathrm{R}=0.5446, \mathrm{P}=0.263861)$. 


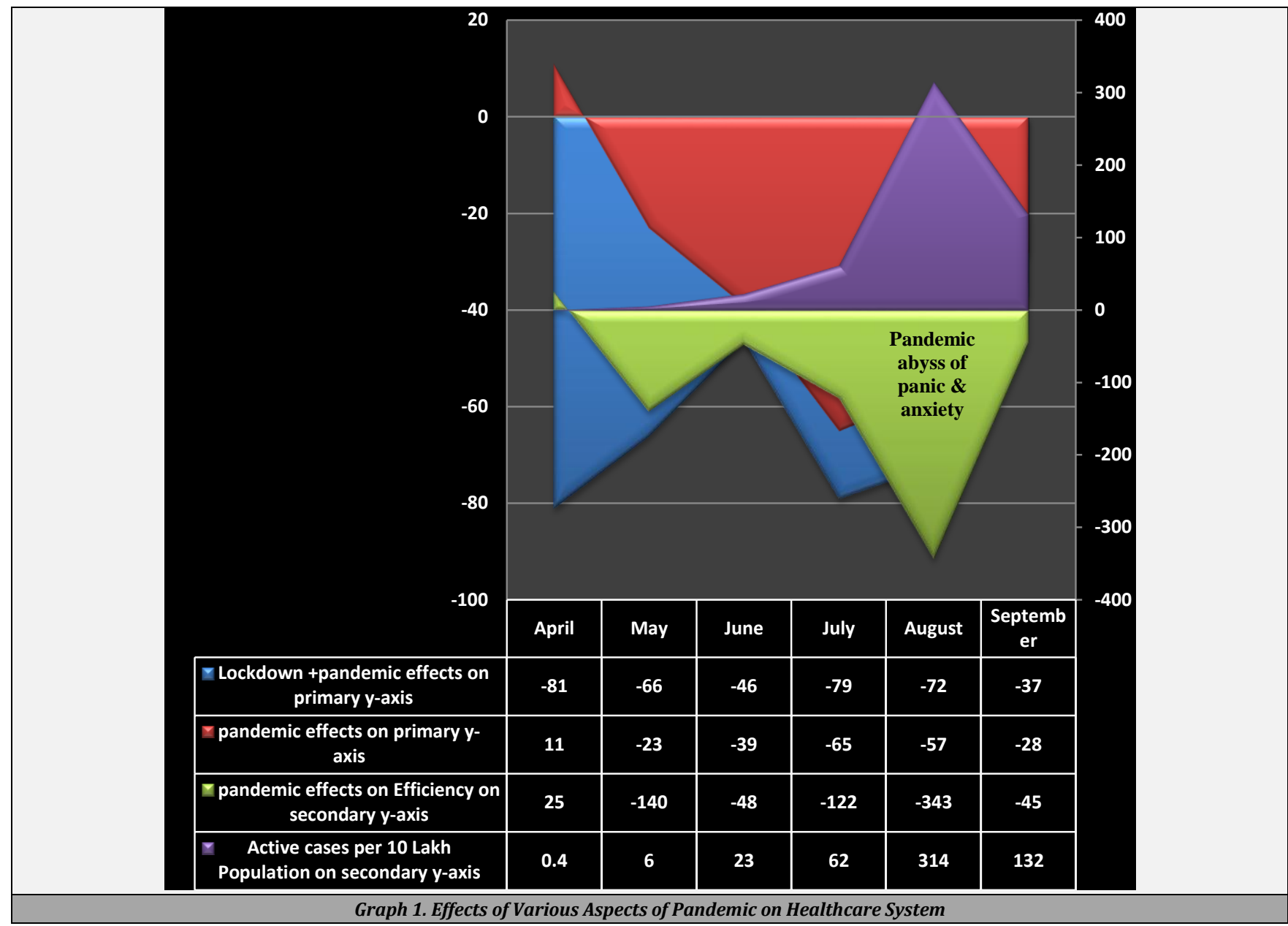

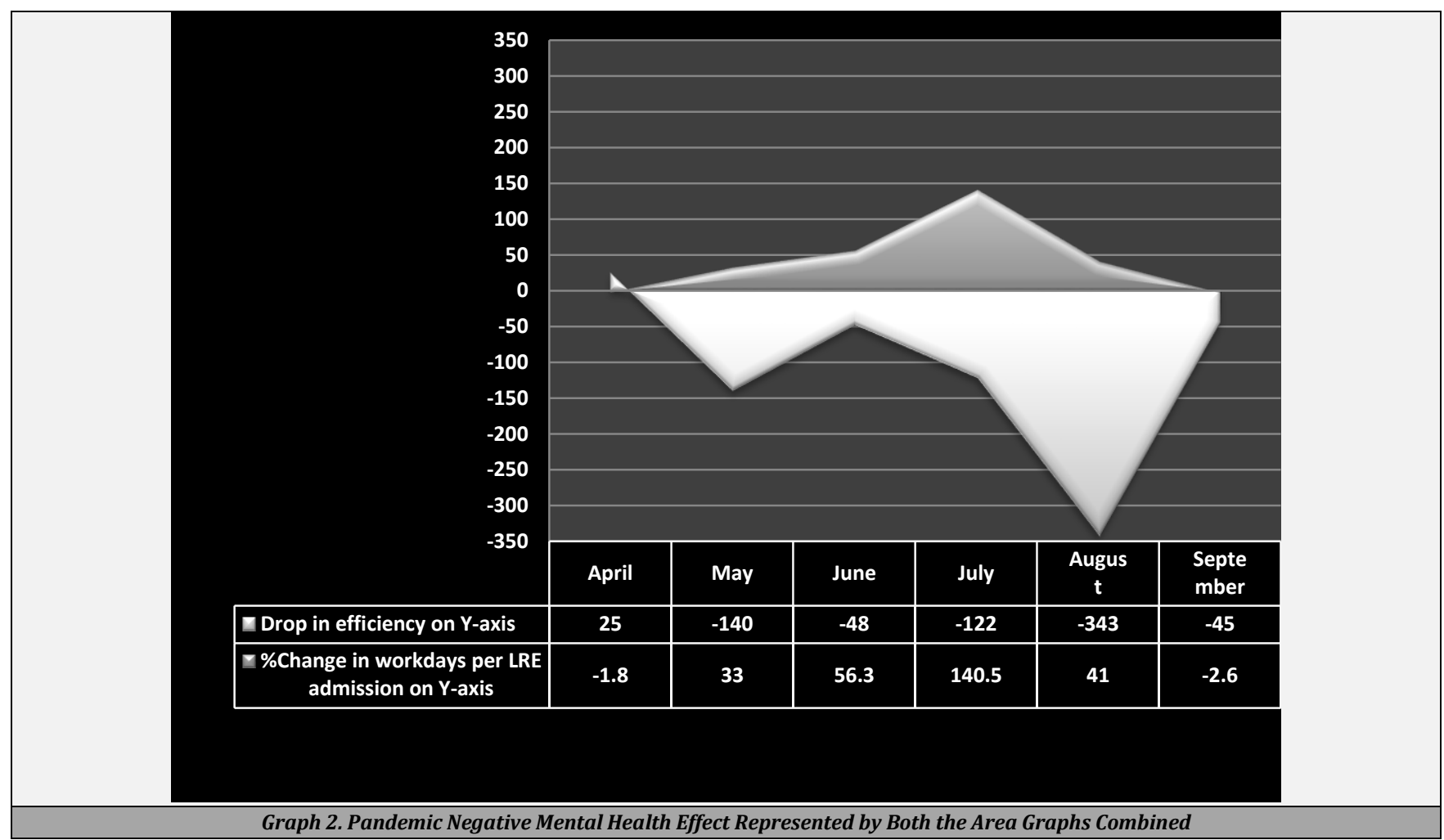




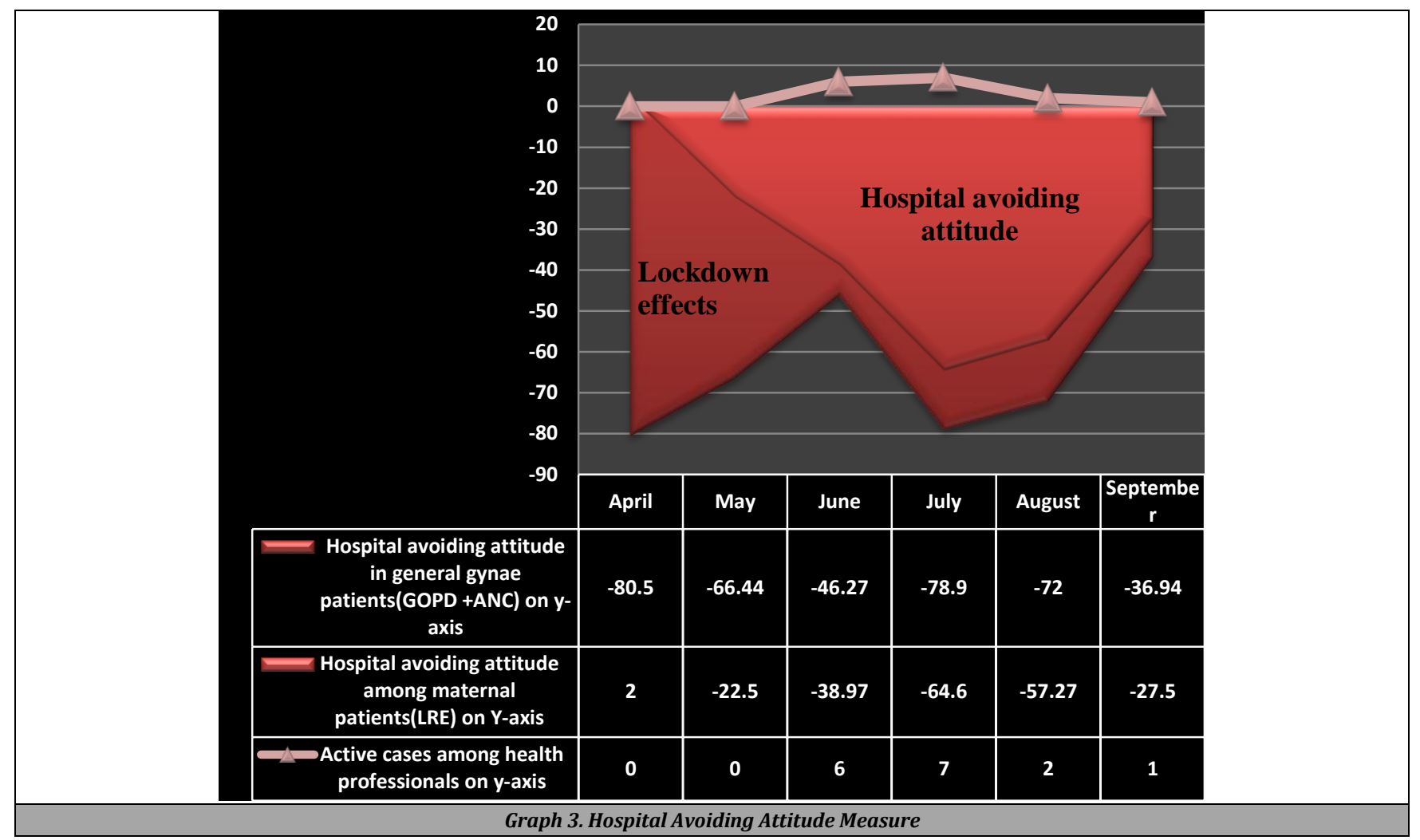

\section{DISCUSSION}

As per Table 2, Month of April seems completely unaffected by pandemic as shown by positive change $(+25)$ in healthcare efficiency indicators while effects on input indicators were mainly due to lockdown, and initial decision by various government hospitals to shutdown Outpatient Departments (OPDs) and elective cases to prepare for the pandemic. Better results for efficiency indicators can be explained due to phase of ignorance as there was least fear of Covid-19.

Among indicators GOPD ( $\mathrm{t}=-11.788, \mathrm{P}<0.00001)$ seems to be most negatively affected by both pandemic and lockdown effects, while Normal delivery rate showed positive rise which can be attributed to lower admissions and reluctance on part of healthcare professionals for surgical interventions in fear of Covid-19 and difficulty in working with PPE kit.

As per Figure 1, area graph for effect on GOPD and ANC shows two peaks downwards at April and July coinciding with the strict lockdown period by central government in April 2 and reinforcement of lockdown strictness by state government in July ( $16^{\text {th }}$ to $\left.31^{\text {st }}\right) .^{8}$

The peak (downward) of area graph of LRE admissions effect coincides with the second peak (downward) of area graph of effect on GOPD and ANC, as both were badly affected in July due to add up effect of restrictness by government and upsurge of Covid-19 infections among the healthcare professionals in our health centre, which occurred in last week of June (six junior doctors of the LRE got infected with Covid19) ${ }^{9}$ leading to increased hospital avoiding attitude of patients.

The area graph for effect on healthcare efficiency shows two peaks (May and August) downwards, first one was during which most of the private clinics were closed, 10 there was denial of treatment due to fear and confusion and slow testing rates for Covid-19 as per only availability of RT-PCR tests making total of high risk pregnancies $72 \%$ and referred cases
$21 \%$ of LRE admissions in May which were highest during the study period, leading to increased mortality by $141 \%$ in comparison to May 2019.

Peak of active cases in Bihar (314 per 10 lakh populations on 16 August) strikingly coincided with phase of worst effect on efficiency (shown by negative peak in green) of healthcare. As increased number of people were getting infected and disease was encompassing more healthcare professionals and their family members, creating a cocoon of panic, anxiety and fear leading to mental incompetency exertion due to working in PPE kits and reluctance to treat Covid-19 suspect patients resulted in increased load of morbid, high risk and immediately succumbing maternal patients and increased still birth rate (8.88) in our tertiary health center. In addition to this as two major tertiary healthcare centers were declared dedicated Covid-19 hospital ${ }^{11}$ so, majority of morbid maternal patients were catered in our center.

Both the area graphs (efficiency and active cases) showed declining trend during September, owing to strong implementation of preventive measures and putting strong efforts on increased testing of people for Covid-19 and emphasis on contact that led to drop of active cases by $58 \%$ and in the meantime increased awareness, > $90 \%$ availability of PPE kits and masks, > $90 \%$ \% (c( ( following of preventive behaviors like wearing masks, social distancing, hand washing among healthcare workers along with use of rapid antigen kit tests for screening of all the patients being admitted, and specially motivating healthcare professionals to work with positive attitude, led to decreased negative effect on efficiency by $87 \%$.

Figure 2 is a symbolic presentation of deep negative impact on efficiency of health professionals during pandemic leading to worst performance as healers themselves are in need of care. Figure 3 depicts the influence of surge of Covid19 infection among health professionals on hospital avoiding attitude of patients. 
In our study total LRE admissions decreased by $35.3 \%$ slight lower than $49.8 \%$ in a retrospective analysis of deliveries in four tertiary care centers in India done by Kumari $\mathrm{V}$ et al. ${ }^{12}$ Increase in still birth rate $(23 \%)$ was similar to a modelling report by researchers from the Johns Hopkins Bloomberg School of Public Health, that says 13 countries could see a $20 \%$ increase or more in the number of stillbirths over a 12 month period 5 but was much lower than Khalil et al. (JAMA, 2020) study. ${ }^{13}$

According to Tam CW T et al. study, during acute health crises, healthcare services are placed under tremendous pressure, making working life even more stressful than normal. ${ }^{14}$

As in this study improvement of efficiency and attitude of patients after full implementation of preventive measures and awareness, proves the perceived efficacy of the training and personal protective equipment that healthcare professionals receive as well as the general quality of organizational leadership and communication similar findings with the other studies.15,16,17 These factors are important not just for motivation - they are also associated with better psychological outcomes in healthcare professionals on the front line during epidemics.

\section{CONCLUSIONS}

Negative psychological impact of a pandemic could not be ignored. Strong emphasis should be on positive counselling of both the health professionals and patients along with the implementation of preventive measures. Healthcare professionals are also human beings and being affected by the anxiety and fear of any unknown catastrophe is a natural human instinct and with the lack of proper resources to fight against it increases the panic. This explains the worsening of healthcare efficiency with increased active cases. Apprehension due to the rapid spread of the pandemic resulted in hospital avoiding behaviour among pregnant women.

Lockdown appears to be two-edged sword as it prevented the spread of Covid-19, but mortality due to other causes increased. Appearance of rapid antigen kits for screening, was an important step in fighting against pandemic leading to early detection of cases and mitigation of fear of contracting Covid19 resulting in promptness of healthcare professionals in treating patients.

\section{Limitations of the Study}

- $\quad$ Single centre study.

- Long term effects could not be known due to short duration of study.

Data sharing statement provided by the authors is available with the full text of this article at jemds.com.

Financial or other competing interests: None.

Disclosure forms provided by the authors are available with the full text of this article at jemds.com.

\section{REFERENCES}

[1] World Health Organization. WHO Director-General's opening remarks at the media briefing on COVID-19. 2020. Accessed 8/10/2020.

[2] https://m.economictimes.com/news/politics-andnation/india-will-be-under-complete-lockdownstarting-midnight-nareandramodi/articleshow/74796908.cms. Accessed 10/10/2020

[3] WHO. Managing epidemics: key facts about major deadly diseases. World Health Organization 2018. Accessed 10/10/2020.

[4] Ji Y, Ma Z, Peppelenbosch MP, et al. Potential association between COVID-19 mortality and health-care resource availability. Lancet Global Health 2020;8(4):e480.

[5] A neglected tragedy: the global burden of stillbirths. http://uni.cf/stillbirthreport. Accessed 10/10/2020.

[6] https://www.censusindia.gov.in/vital_statistics/AHSBull etins/AHS_Factsheets_2011_12/Bihar_Factsheet_201112.pdf. Accessed 8/10/2020.

[7] https://twitter.com/BiharHealthDept. Accessed on $4 / 10 / 2020$.

[8] https://www.firstpost.com/india/complete-lockdownin-bihar-from-16-to-31-july-petrol-pumps-banks-to-beopen-schools-colleges-to-be-shut-for-16-days8600291.html. Accessed 10/10/2020.

[9] https://m.timesofindia.com/city/patna/40-pmch-docsparamedical-staff-undergo-covid-19test/amp_articleshow/76516907.cms. Accessed on 10/10/2020.

[10] https;//theprint.in/health/staff-testing-covid-positiveforce-bihar-private-hospitals-to-shut-doors-on-noncovid-patients/463747/Accessed 10/10/2020.

[11] https://timesofindia.indiatimes.com/city/patna/aiimsp-4th-dedicated-covid-hospital-inbihar/articleshow/76901236.cms. Accessed on 10/10/2020.

[12] Kumari V, Mehta K, Choudhary R. COVID-19 outbreak and decreased hospitalisation of pregnant women in labour. Lancet Glob Health 2020;8(9):e1116-7.

[13] Khalil A, Von Dadelszen P, Draycott T, et al. Change in the incidence of stillbirth and preterm delivery during the COVID-19 pandemic. JAMA 2020;324(7):705-6.

[14] Tam CWC, Pang EPF, Lam LCW, et al. Severe acute respiratory syndrome (SARS) in Hong Kong in 2003: stress and psychological impact among frontline healthcare workers. Psychol Med 2004;34(7):1197-204.

[15] Devnani M. Factors associated with the willingness of health care personnel to work during an influenza public health emergency: an integrative review. Prehosp Disaster Med 2012;27(6):551-66.

[16] Aiello A, Young-Eun KM, Raja S, et al. Resilience training for hospital workers in anticipation of an influenza pandemic. J Contin Educ Health Prof 2011;31(1):15-20.

[17] Cates DS, Gomes PG, Krasilovsky AM. Behavioral health support for patients, families and healthcare workers. Bioemergency Planning 2018: p. 195-214. 